\title{
Fatigue design challenges in aerospace industry: Recent linear and nonlinear models
}

\author{
Dimitrios Pavlou \\ Dept. of Mechanical and Structural Engineering and Materials Science, University of Stavanger, \\ Norway. Email: dimitrios.g.pavlou@uis.no
}

\begin{abstract}
Reliable fatigue design rules affect the proactive identification of safety parameters in aerospace industry. Numerous fatigue crack initiation and propagation models, linear and nonlinear, have been developed for designing purposes or estimation of the remaining life of aging airplanes. Depending on the adopted assumptions, the accuracy varies for different loading histories, loading types, and materials. Semi empirical models are simple but yield significant inaccuracies. Models with better theoretical basis provide better accuracy, but implementation in real conditions is problematic. In the present work, a review of author's recent fatigue crack initiation and propagation models based on physical mechanisms is presented and improvements are proposed. Verification of the models on test results is provided and discussed.
\end{abstract}

Keywords: fatigue, damage, crack initiation, crack propagation, nonlinear models, crack growth retardation

\section{Introduction}

Successful structural design and data driven safety assessment require reliable fracture mechanics tools for fatigue damage accumulation modelling. Palmgren and Miner were the first who attempted to calculate the fatigue damage $[1,2]$. Due to its simplicity, their fatigue damage accumulation rule is widely used. However, the Palmgren-Miner's rule is inconsistent with the nonlinear material damage mechanisms [3,4]. Depending on the type of loading history, the Miner's rule can overestimate or underestimate the fatigue damage accumulation prediction [5]. Its accuracy is better for loading spectra containing high stress levels. The above rule is linear and does not take into account the loading sequence effect and the material damage accumulation theory. The Miner's rule can be used for crack initiation only. Manson and Halford $[6,7]$ have improved the linear fatigue damage rule. Their double-linear damage model (DLDR) preserves (to some extend) the simplicity of PalmgrenMiner's rule and takes into account two different fatigue mechanisms. They have proposed two fatigue stages in order to model both the crack initiation and crack propagation phases. However, the load interaction effects [8,9] and the mixed mode fatigue crack propagation [10-12] are not accounted for. Known nonlinear models are based on continuum damage theory [13], isodamage straight lines [e.g. 14, 15], and Manson-Halford's concept [16]. Further literature review on nonlinear damage accumulation models has been published recently [17]. For crack propagation modelling the Paris rule [18] is well known. However, this old rule is linear, and therefore it does not take into account the load interaction effects $[19,20]$. Modification of this rule has been attempted by Wheeler [21] and Willenborg [22] in order to improve the fatigue crack growth prediction for loading histories containing overloads. However, the modelling of the retardation effects has semi empirical basis. Elber [23-25] is the first who modelled the crack closure as a predominant mechanism for 
overload-induced fatigue crack growth retardation. The proposed model yields accurate results for structural elements subjected to conditions where the crack closure mechanism is predominant (large overload-induced plastic zones).

However, apart from the crack closure mechanism due to residual plastic deformation, more than four other material mechanisms affecting the fatigue crack growth are known, i.e. strain hardening of the material within the overload crack-tip plastic zone [e.g. 26, 27], plastic blunting and resharpening [28], fracture surface roughness which causes contact between the crack faces at nonzero loads reducing the effective $\Delta K[29-31]$, and crack branching $[9,10]$.

In the present work, the new crack initiation theory of the S-N fatigue damage envelope [32], developed by the author, will be implemented on Al-2024 specimens subjected to high-low (H-L) and low-high (L-H) two-stage loading. Moreover, the overload-induced crack growth retardation model $[26,27,33,34]$ based on strain hardening, will be improved to take into account both overload and underload effects.

\section{Fatigue crack initiation}

A recent advance in fatigue crack initiation modelling is based on the proposal that the area bounded by the $\mathrm{S}$ and $\mathrm{N}$ axes and the $\mathrm{S}-\mathrm{N}$ curve can provide a damage map for the material [32].

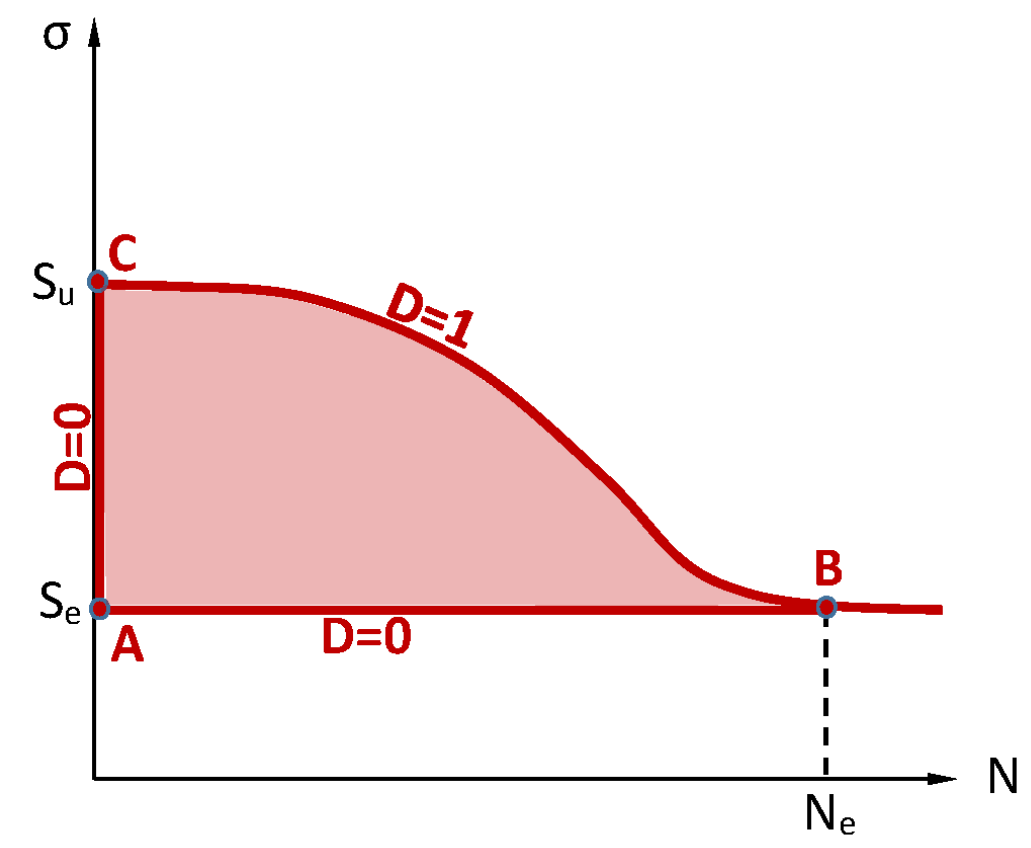

Fig. 1: The S-N damage envelope

The boundary AB of the envelope (Fig. 1) corresponding to the endurance limit $S_{e}$ should be considered as an isodamage line with damage $D=0$. The boundary $A C$ (Fig. 1) corresponds to number of loading cycles $N=0$. Therefore, it should also be considered as an isodamage line with $D=0$. Moreover, the boundary $\mathrm{CB}$ is the $\mathrm{S}-\mathrm{N}$ curve corresponds to crack initiation, i.e. $\mathrm{D}=1$. Finite element 
analysis performed in [32] has derived a damage map and isodamage lines. Using the following dimensionless parameters for stress and loading cycles

$$
\sigma_{i}^{*}=\frac{\sigma_{i}-S_{e}}{S_{u}-S_{e}} \quad 0 \leq \sigma_{i}^{*} \leq 1
$$

$n_{i}^{*}=\frac{n}{N_{e}} \quad 0 \leq n_{i}^{*} \leq 1$

the damage zones for Al-2024 have been derived with the aid of ANSYS [32, 35] and are demonstrated in Fig. 2. The colours of the damage zones correspond to $\log (D)$. Therefore, taking
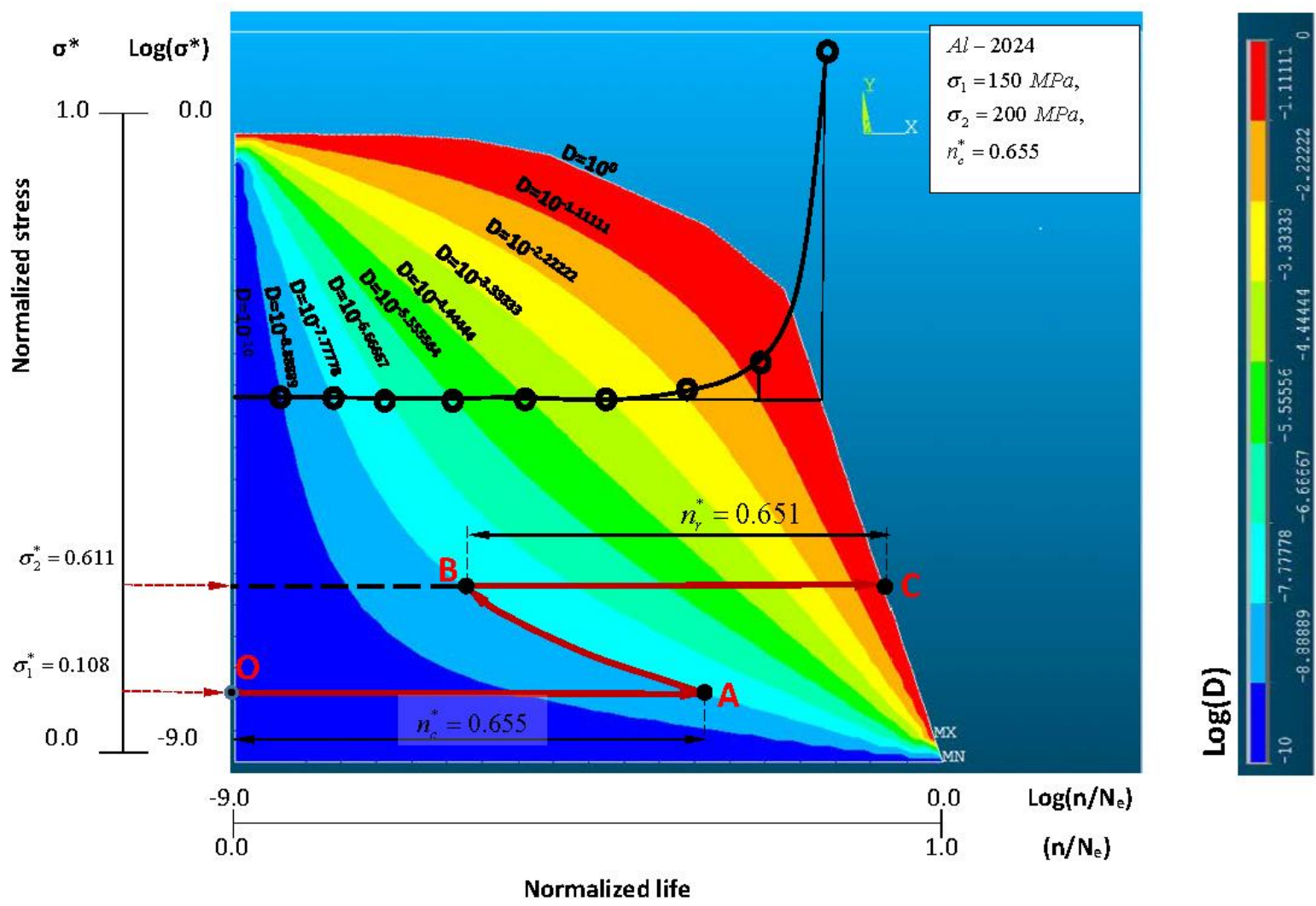

Fig. 2: Damage zones for Al-2024 
into account the vertical legend of colors for $\log (D)$, the isodamage lines correspond to values $D=10^{-10}, 10^{-8.88889}$, $10^{\circ}$. Using the results of Fig. 2, damage curves $D$ vs $n / N_{f}$ have been derived in Fig. 3 for stress levels $\sigma^{*}=0.088,0.248,0.408,0.888$.

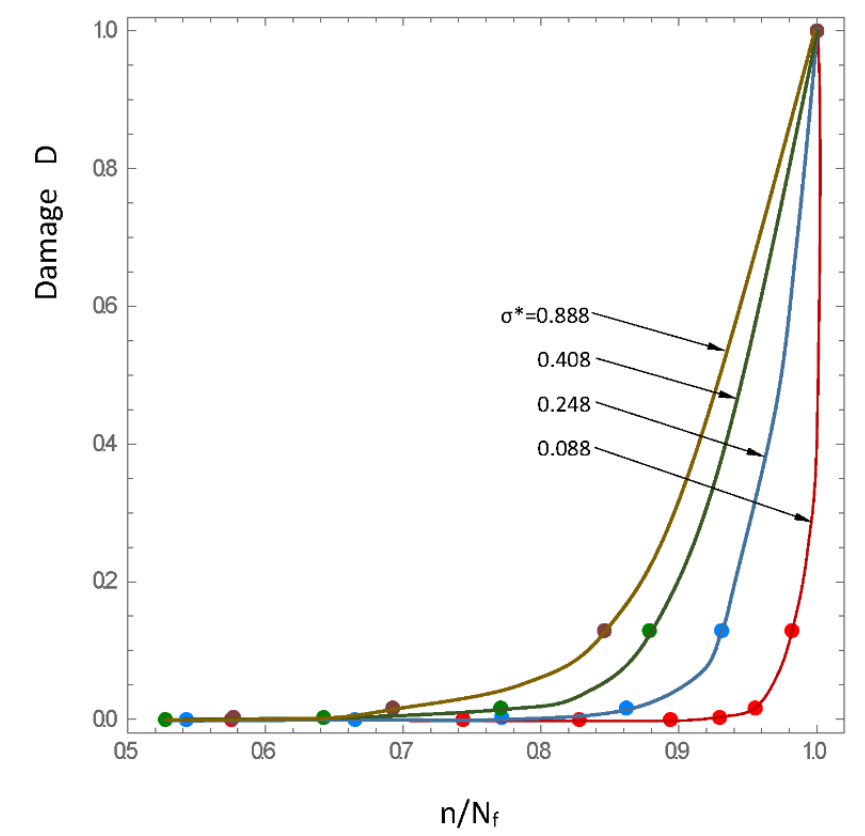

Fig. 3: Damage curves for Al-2024

The damage envelope in Fig. 2 can be used for the calculation of the remaining life for two-stage loading (Fig. 4). For a loading block with stress level $\sigma_{1}=150 M P a$ (i.e. $\sigma_{1}^{*}=0.108$ ) and loading period $n_{c}^{*}=0.655$ (consumed life), the accumulated damage is $D=10^{-7.77778}$ (point A in Fig. 2). The continuation of the loading for a higher stress $\sigma_{2}=200 M P a$ (i.e. $\sigma_{2}^{*}=0.611$ ) should start from the already accumulated damage $D=10^{-7.77778}$ corresponding to point $\mathrm{B}$ (same isodamage line with point $\mathrm{A}$ ). The remaining life is demonstrated by the segment $\mathrm{BC}$, i.e. $n_{r}^{*}=0.651$. This procedure is followed by a number of loading data $\mathrm{H} / \mathrm{L}$ and $\mathrm{L} / \mathrm{H}$ borrowed by the ref. [36] and the results are shown in Figs 5.

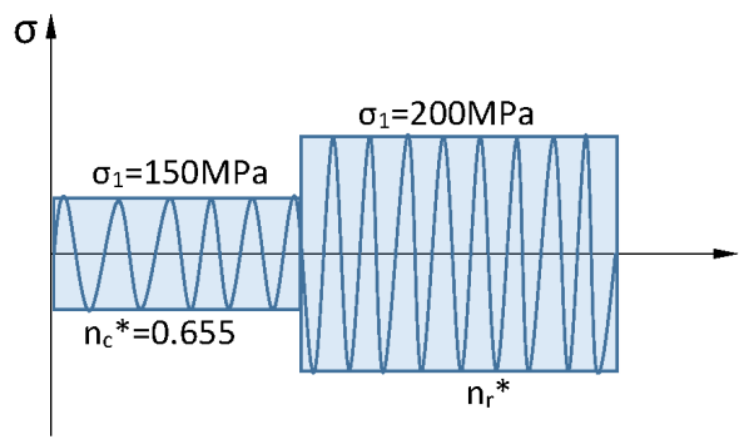

Fig. 4: Example of two-stage loading 

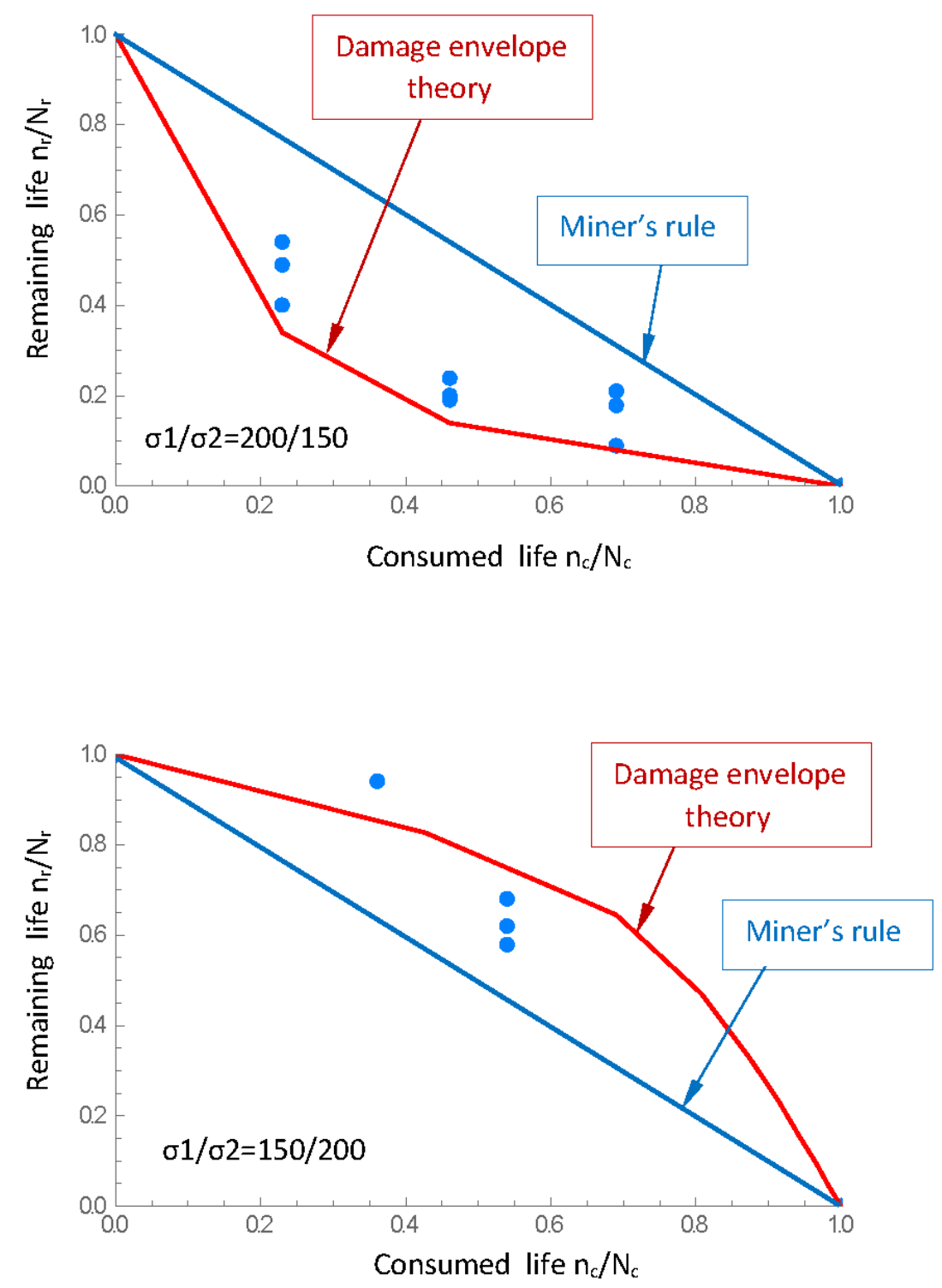

Fig 5: Remaining life predictions for Al-2024 specimens subjected to $\mathrm{H} / \mathrm{L}$ and $\mathrm{L} / \mathrm{H}$ two-stage loading

The results indicate that the S-N damage envelope theory provides successful predictions of the remaining life for these loading cases. Unlike the above nonlinear predictions, Miner's rule has overestimated the remaining life for $\mathrm{H} / \mathrm{L}$ loads, and has underestimated it for the inverse loading sequence.

\section{Fatigue crack propagation}

Variable amplitude loading sequences are associated with transient effects in fatigue crack growth. Overloads yield significant retardation in the fatigue crack growth rate, and underloads reduce the 
above effect. Among the proposed tools for fatigue crack growth prediction for variable amplitude loading, Wheeler's [21], Whillenborg's [22], and Elber's [23] models are the most known, and have been used for further improvements [37-40]. Wheeler's and Whillenborg's models have semi empirical basis. Elber's model and its improvements take into account the overload retardation effect due to the crack closure mechanism [41-44] and provide accurate predictions for loading cases where the crack closure mechanism is dominating the fatigue crack growth. The first attempt for modelling the effect of the material hardening within the overload plastic zone took place in 1995 $[26,27]$. In the original version of this research, the crack growth rate after an overload is correlated to the actual yield stress of the hardened material within the overload plastic zone. The main idea is based on the assumption that the baseline plastic zone in the crack tip (Fig. 6) is subjected to lowcycle-fatigue conditions due to high strain amplitude [26, 27, 33, 34].

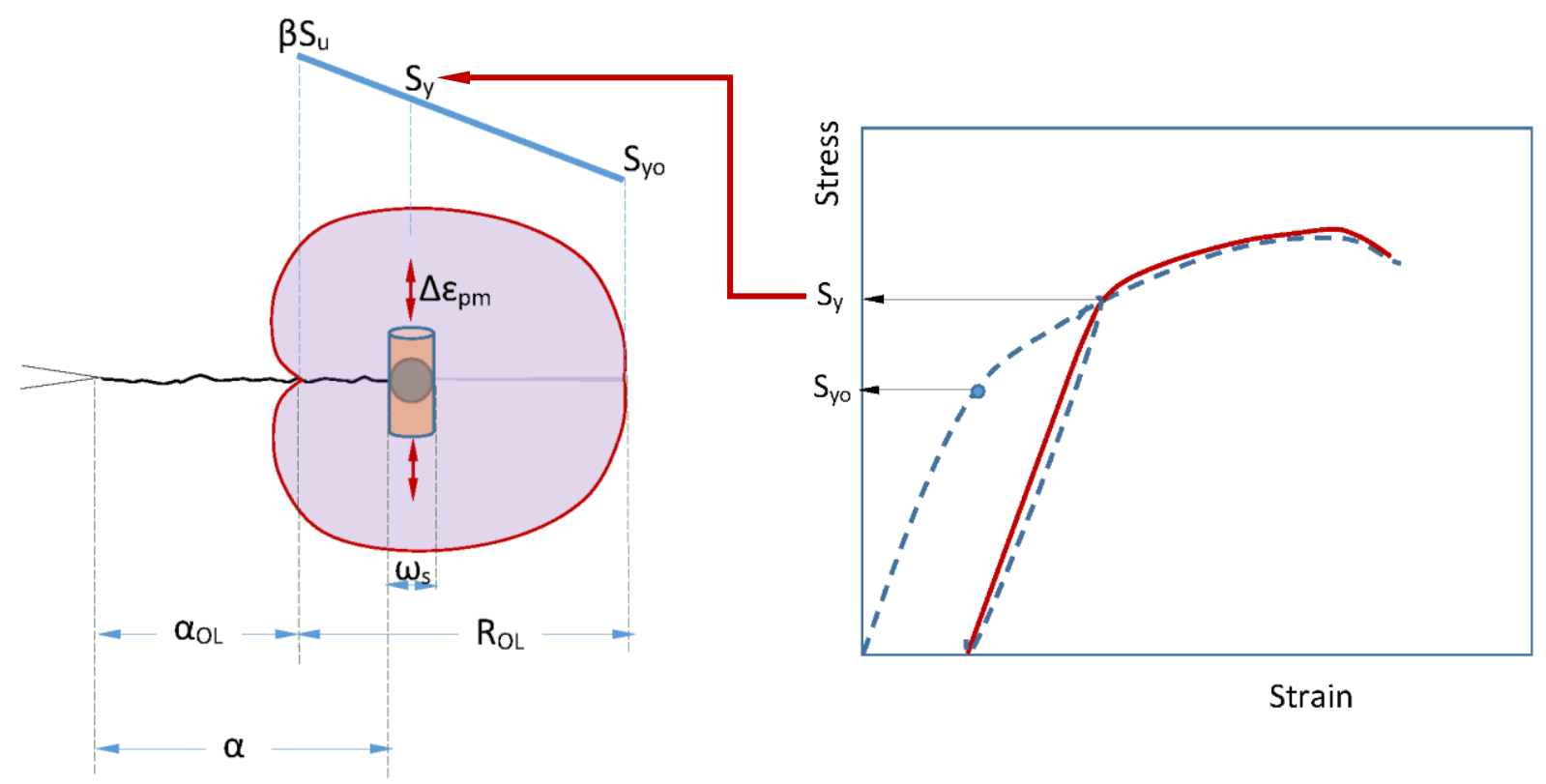

Fig. 6: Strain hardening-induced fatigue crack growth retardation model

The fatigue crack growth rate $d a / d N$ is approximated by the formula

$$
\frac{d a}{d N}=\frac{\omega_{s}}{\Delta N}
$$

where $\omega_{s}$ is the plastic zone size (Fig. 6) of the constant amplitude loading $\Delta \sigma$ (Fig. 7), and $\Delta N$ is the required number of cycles for crack growth by a length $\omega_{s}$. With the aid of Coffin-Manson 


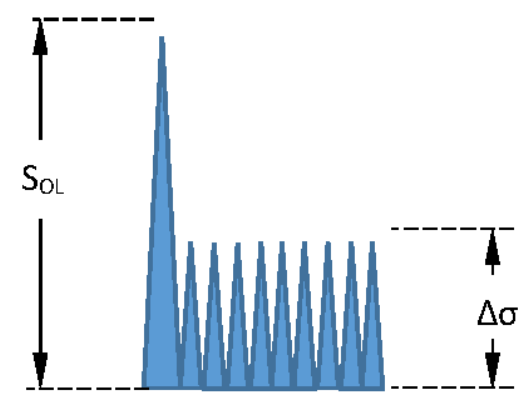

Fig. 7: Constant amplitude loading containing an overload

rule for low cycle, and following fracture mechanics analysis, the following crack growth retardation model is proposed:

$$
\frac{d a}{d N}=\frac{\pi}{32}\left(\frac{1}{2 K_{c r}^{2}}\right)^{1 / m} \frac{\Delta K^{2(1+1 / m)}}{S_{y}^{2}}
$$

where $S_{y}$ is the actual yield stress of the hardened material within the overload plastic zone (Fig. 6). Depending on the location of the crack tip, the $S_{y}$ of the hardened material takes values $S_{y}=S_{u}$ for $a=a_{O L}$ (immediately after the overload), and $S_{y}=S_{y o}$ for $a=a_{O L}+R_{O L}$ when the retardation effect ends. A simple linear distribution of the $S_{y}$ between the boundary values $S_{u}, S_{y o}$ is assumed, and a retardation factor

$$
\lambda=\left(\frac{S_{y o}}{S_{y}}\right)^{2} \quad\left(S_{y o} / S_{u}\right)^{2} \leq \lambda \leq 1
$$

is derived. Since the power of the ratio $\left(S_{y o} / S_{y}\right)$ is 2 , the effect of the strain hardening seems to dominate the overload-induced retardation. However, the above model does not take into account the effect of underloads. It is well known that underloads eliminate the retardation effect of overloads [e.g. 45]. An underload with stress $\sigma_{U L}=-\sigma_{O L}$ can cancel the retardation effect of the overload. Therefore, a correction factor

$\beta=\left(\frac{S_{y o}}{S_{u}}-1\right) \frac{\left|\sigma_{U L}\right|}{\left|\sigma_{O L}\right|}+1$

is proposed to adjust the value of the parameter $S_{u}$ in Fig. 6. Therefore,

$$
\beta S_{u}= \begin{cases}S_{y o} & \text { for } \sigma_{U L}=-\sigma_{O L} \\ S_{u} & \text { for } \sigma_{U L}=0\end{cases}
$$


For $\sigma_{U L}=-\sigma_{O L}$ the value of the maximum yield stress of the hardened material (Fig. 6) is $\beta S_{u}=S_{y o}$. In this case $\lambda=\left(S_{y o} / \beta S_{u}\right)^{2}=1$. Therefore, no retardation effect takes place. For $\sigma_{U L}=0$, eq. (6) yields $\beta=1$. Therefore, $\lambda=\left(S_{y o} / S_{u}\right)^{2}$ meaning that considerable retardation occurs. Taking into account the above improvement, the model is applied to the random loading history $\mathrm{M} 90(0.27)$ borrowed by ref. [46]. The above loading contains overloads and underloads. The modified rainflow counting method described in $[26,27]$ is implemented in order to transform the irregular history to a loading history containing full cycles. The theoretical predictions are correlated to test results [46], indicating good agreement (Fig. 8).

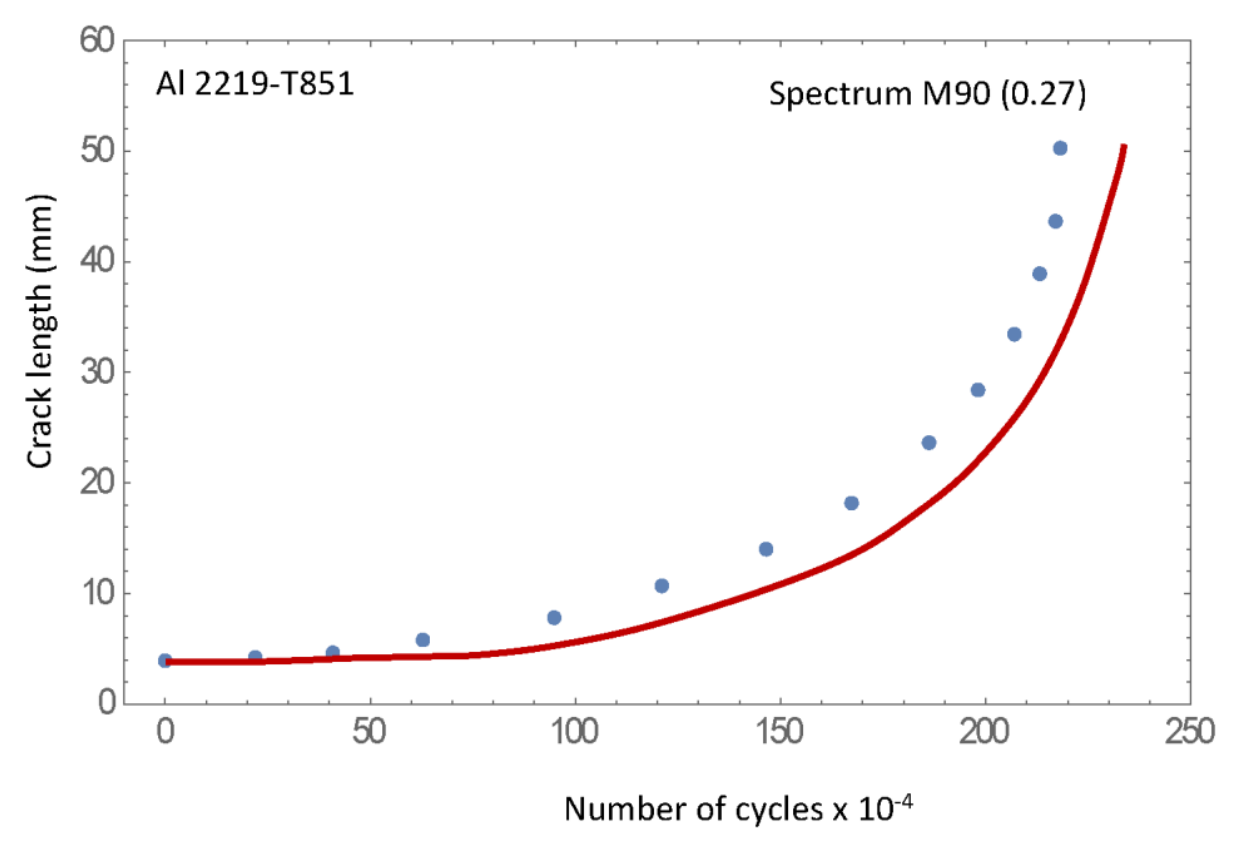

Fig. 8: Correlation of the prediction of the proposed method to test results borrowed from ref. [46]

\section{Conclusions}

1. Fatigue design challenges in aerospace industry have been discussed.

2. Recent advances in fatigue crack initiation and propagation prediction have been presented.

3. Author's recent models and their improvements have been implemented to predict the fatigue crack initiation and propagation in variable amplitude loading cases.

4. Verification of the $\mathrm{S}-\mathrm{N}$ damage envelope theory for crack initiation, and the strain hardening model for crack propagation on test results for Al-2024 and Al-2219 has been provided.

\section{References}

[1] Palmgren A., Die Lebensdauer von Kugellagern. Z Ver Dtsch Ing 1924; 68(14):339-41.

[2] Miner MA. Cumulative damage in fatigue. J Appl Mech 1945; 12(3): A159-64. 
[3] Pavlou D.G. A phenomenological fatigue damage accumulation rule based on hardness increasing for the 2024-T42 aluminum. Engineering Structures, 2002.

[4] Shun-Peng Zhu, Yong-Zhen Hao, José A.F.O. Correia, Grzegorz Lesiuk, Abilio M.P. De Jesus, Nonlinear fatigue damage accumulation and life prediction of metals: A comparative study, Fatigue \& Fracture of Engineering Materials \& Structures, 2018; 1-12, https://doi.org/10.1111/ffe.12937

[5] Rege K., Pavlou D.G., A one parameter nonlinear fatigue damage accumulation model. Int J. of Fatigue, 2017; 98: 234-46.

[6] Manson SS, Halford GR. Practical implementation of the double linear damage rule and damage curve approach for treating cumulative fatigue damage. Int J Fract. 1981;17(2):16992.

[7] Lee Y-L, et al. Fatigue testing and analysis theory and practice. Saint louis, USA: ButterworthHeinemann, 2011.

[8] Pavlou D.G., Prediction of fatigue crack growth under real stress histories. Engineering Structures 22, (2000), 1707-1713.

[9] Pavlou D.G., Vlachakis N.V., Pavlou M.G., Vlachakis V.N., Estimation of fatigue crack growth retardation due to crack branching. Computational Materials Science, 29, (2004), 446-452.

[10] Pavlou D.G., Fatigue crack deflection-induced retardation based on the principle of the minimum potential energy. International Review of Mechanical Engineering (IREME), 2015, 9(3), 324-330.

[11] Pavlou D.G., Mode I+II Fatigue crack growth delay by stop holes. Journal of Aerospace Technology and Management, 2018, 10, 1-11.

[12] Pavlou D.G., Labeas GN, Vlachakis NV, Pavlou FG., Fatigue crack propagation trajectories under mixed-mode cyclic loading. Engineering Structures 25, (2003), 869-875.

[13] D.-G. Shang, W.-X. Yao, A nonlinear damage cumulative model for uniaxial fatigue. Int J Fatigue, 21 (2) (1999), pp. 187-194.

[14] S. Subramanyan, A cumulative damage rule based on the knee point of the S-N curve ASME J Mater Technol, 98 (4) (1976), pp. 316-321.

[25] Z. Hashin, A. Rotem, A cumulative damage theory of fatigue failure. Mater Sci Eng, 34 (2) (1978), pp. 147-160.

[16] H. Gao, et al. A modified nonlinear damage accumulation model for fatigue life prediction considering load interaction effects. Sci World J (2014).

[17] E. Santecchia, et al. A review on fatigue life prediction methods for metals. Adv Mater Sci Eng (2016).

[18] Paris PC, Tada H., Donald JK. Service load fatigue damage - a historical perspective. Int. J. Fatigue 1999;21:S35-46.

[19] Schijve J., Fatigue of Structures and Materials, Springer, 2009.

[20] Suresh S., Fatigue of Materials. Cambridge University Press, 2003. 
[21] Wheeler OE. Spectrum loading and crack growth. J Basic Engng, Trans ASME, Ser D, 1972;94(1):181-6.

[22] Willenborg JD, Engle Jr RM, Wood HA. A crack growth retardation model using effective stress concept. AFDL-TM-71-1-FBR, 1971.

[23] Elber W., Fatigue crack closure under cyclic tension. Engineering Fracture Mechanics 1970;2:37-45.

[24] Bathias C., Plastic Deformation Mechanisms at the Crack Tip, Fatigue of Materials and Structures: Fundamentals, John Wiley and Sons, 2013.

[25] Yang, B., Zhao, Y.-X., Liang, H.-Q., Wu, P.-B., Zeng, J., Elber-type-equation-based probabilistic model for random fatigue long crack propagation, Gong Cheng Li Xue/Engineering Mechanics, Vol. 22, Issue 5, 2005, 99-104.

[26] D.G. Pavlou D.G., Prediction of fatigue crack growth under real stress histories, Engineering Structures, 22 (2000), pp. 1707-1713

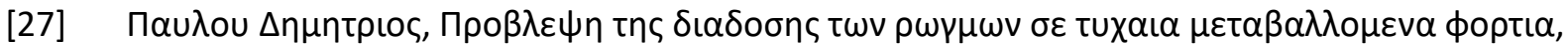
PhD Thesis, University of Patras, 1994.

[28] C.M. Ward-Close, A.F. Blom, R.O. Ritcie, Mechanisms associated with transient fatigue crack growth under variable-amplitude-loading: an experimental and numerical study, Engineering Fracture Mechanics, 32 (4) (1989), pp. 613-638.

[29] M.R. Parry, S. Syngelakis, I. Sinclair, Investigation of roughness induced crack closure effects in fatigue, A.P.S. Selvadurai, C.A. Brebbia (Eds.), Proc. of the 6th Int. Conf. of Damage and Fracture Mechanics, Montreal, WIT Press, Southampton (2000), pp. 313-322.

[30] H.R. Mayer, S.E. Stanzl, E.K. Tschegg, J. Schijve, Fatigue crack growth of Al 2024-T3 under low amplitude two-step loading, Fatigue Fract. Engng. Mater. Struct., 15 (3) (1992), pp. 265-275.

[31] N. Louat, K. Sadananda, M. Duesbery, A.K. Vasudevan, A theoretical evaluation of crack closure, J. Metall. Trans., 24A (1993), pp. 2225-2232.

[32] Pavlou D.G., The theory of the S-N fatigue damage envelope: Generalization of linear, double-linear, and non-linear fatigue damage models, International Journal of Fatigue 110, (2018), 204-214.

[33] Pavlou D.G., The influence of the crack tip plastic zone strain hardening on the metal highcycle-fatigue behaviour, N. Jones, D.G. Talaslidis, C.A. Brebbia, G.D. Manolis (Eds.), Proc. of the 5th Int. Conf. on Structures under Shock and Impact (SUSI 98), Thessaloniki, Computational Mechanics Publications, Southampton (1998), pp. 633-647.

[34] Pantelakis S, Kermanidis Th, Pavlou D., Fatigue crack growth retardation assessment of 2024T3 and 6061-T6 aluminum specimens, J. Theoret. Appl. Fract. Mech., 22 (1995), pp. 35-42.

[35] https://www.ansys.com/

[36] Pavlou D.G., A phenomenological fatigue damage accumulation rule based on hardness increasing for the 2024-T42 aluminum, Engineering Structures 24 (2002) 1363-1368. 
[37] Shan Jiang, Wei Zhang, Xiaoyang Li, and Fuqiand Sun, An analytical model for fatigue crack propagation prediction with overload effect, Mathematical Problems in Engineering, Vol 2014, article ID 713678, p. 1-9.

[38] Jiang Shan, Zhang Wei, He Jingjing, Wang Zili, Comparative study between crack closure model and Willenborg model for fatigue prediction under overload effects, Chinese Journal of Aeronautics, 2016, 29(6), 1618-1625.

[39] Marcos Venicius Soares Pereira, Fathi Aref Ibrahim Darwish, Arnaldo Freitas Camarao, Sergio Henrique Motta, On the prediction of fatigue crack retardation using Wheeler and Willenborg models, Materials Research, 10(2), 101-107, 2007.

[40] Michal Jasztal, Dorota Kocanda, Henryk Tomaszek, Predicting fatigue crack growth and fatigue life under variable amplitude loading, Fatigue of Aircraft Structures, Vol. 1, 2010, 37 51.

[41] Khan S.U., Alderliesten R.C., Scjijve J., Benedictus R., On the fatigue crack growth prediction under variable amplitude loading, in: Computational and Experimental Analysis of Damaged Materials 2007, Editor: Dimitrios G. Pavlou, Research Signpost 2007, 77-106.

[42] Luiz Carlos H. Ricardo, Carlos Alexandre J. Miranda, Crack simulation models in variable amplitude loading - a review, Frattura ed Integrita Strutturale, 35 (2016), 456-471.

[43] Ricardo L.C.H., Andrade A.H.P., Topper T.H. (2008), The use of retardation models in crack propagation simulation. Proc. of SAE Brazil Congress Society of Automotive Engineers, Article 2008-36-0007.

[44] Ribeiro A.S., Jesus A.P., Costa J.M., Borrego L.P., Maeiro J.C., Variable amplitude fatigue crack growth modelling, $8^{\text {th }}$ Congresso Nacional de Mecanica Experimental Guimaraes, 2010, 2123.

[45] Huang Xiaoping, Torgeir Moan, Cui Weicheng, An experimental model of fatigue crack growth under variable amplitude loading. Int. J. Fatigue 30 (2008) 2-10.

[46] Newman Jr. J.C., A crack closure model for predicting fatigue crack growth under aircraft spectrum loading, in: Methods and Models for predicting Fatigue Crack Growth under Random Loading, editors: Chang/Hudson, STP 748, ASTM 1981. 